\title{
ARTRITE E ARTROSE: ASPECTOS GERAIS E TRATAMENTO MEDICAMENTOSO
}

\section{ARTHRITIS AND ARTHROSIS: GENERAL ASPECTS AND DRUG TREATMENT}

\section{Paula Pinheiro Gois;}

Estudante do curso de ciências biológicas da Universidade Federal de Viçosa Estado de Minas Gerais.

Brasil.

Paloma Benígno Morais

Mestre em Ciências Biológicas pela Universidade Vale do Rio Doce, Docente da Faculdade Presidente Antônio Carlos de Teófilo Otoni, Estado de Minas Gerais. Brasil.

Carla Fiuza

Médica pela Universidade Federal de Minas Gerais (UFMG), Residência em Pediatria pelo Hospital São Francisco, Docente da Faculdade Presidente Antônio Carlos de Teófilo Otoni, Estado de Minas Gerais. Brasil.

\section{RESUMO}

Artrite e artrose são doenças similares, degenerativas que atacam as articulações. O objetivo desta pesquisa foi identificar as características gerais de ambas as doenças - a primeira é causada por um processo inflamatório nas articulações de determinado local e tem como sintomas dor, vermelhidão e inchaço; já a segunda, é uma doença degenerativa que ocorre pelo desgaste do tecido conjuntivo cartilaginoso nas articulações; seus sintomas são parecidos, mas incluem rigidez, dormência e rangido nos movimentos. O presente artigo também enfoca o tratamento medicamentoso, apesar de haver outros tipos de terapias como a intra-articular, a artroscopia, a osteonomia, a artroplastia e a artrodese. Grande parte dos fármacos são os anti-inflamatórios e analgésicos indicados para o controle da dor causada por esses distúrbios. Enfatiza-se que artrite não tratada pode evoluir para uma artrose, e artrose crônica pode se tornar aguda e acarretar um novo tipo de artrite.

Palavras-chave: Artrite; Artrose; Articulações; Tratamento 


\begin{abstract}
Arthritis and Arthrosis are similar and degenerative diseases that attack the joints. The aim of this research was to identify the general characteristics of both diseases - the first is caused by an inflammatory process in the joints of a certain place, its symptoms are pain, redness and swelling, the second is a degenerative disease that occurs due to the wear of the cartilage connective tissue in the joints, its symptoms are similar but include stiffness, numbness and creaking in movements - as well as possible drug treatments. The inflammation of the synovial joints is called arthritis, while the corrosion of the cartilage in the joints characterizes the condition called arthrosis. This article focuses on drug treatment although there are other types of therapiessuch as intra-articular, arthroscopy, osteonomy, arthroplasty and arthrodesis. Most drugs are anti-inflammatory and analgesic indicated to control the pain caused by these disorders. It is emphasized that untreated arthritis can progress to arthrosis, and chronic arthrosis can become acute and lead to a new type of arthritis.
\end{abstract}

Keywords:Arthritis; Arthrosis; Joints; Treatment

\title{
1 INTRODUÇÃO
}

O tecido conjuntivo é responsável pelo estabelecimento e manutenção da forma do corpo, isso ocorre por conta de um conjunto de moléculas (matriz) que conecta células e órgãos. Do ponto de vista morfológico, é composto por células, fibras e substância fundamental amorfa (um dos componentes da matriz extracelular). A matriz consiste em diferentes combinações de proteínas fibrosas e de substância fundamental (JUNQUEIRA, 2004).

Originado do mesênquima (tecido embrionário com células alongadas e nucléolo proeminente), esse tecido possui várias funções além da estrutural, como reserva de hormônios que controlam o crescimento e a diferenciação celular, constituição do estroma (tecido de sustentação) e formação de tendões, ligamentos e membranas envoltórias, e ainda está presente nas articulações (JUNQUEIRA, 2004).

Essas, também denominadas de junturas, são locais de conexões entre dois ou mais ossos ou entre cartilagens, responsáveis por permitir a movimentação dos membros. Existem alguns tipos de articulações: as fibrosas ou sinartroses que possuem separação pelo tecido conjuntivo fibroso e não apresentam cavidade articular, e ainda são divididas em suturas e sindesmoses; as cartilaginosas ou anfiartroses que possuem separação por tecido conjuntivo cartilaginoso e 
não possuem cavidade articular, são divididas em sincondroses e sínfises; e, finalmente, as articulações sinoviais, também chamadas de diartroses, que possuem uma cavidade articular denominada de cavidade sinovial e junto a ela, uma bolsa cheia de líquido sinovial que age como lubrificante. Dependendo do movimento, essas articulações podem se denominadas de uniaxial, as quais permitem um eixo de rotação, biaxial, dois eixos de rotação, poliaxiais, três ou mais eixos (PINHEIRO, 2010).

Este trabalho foca-se em duas doenças: a artrite e a artrose que são patologias que atacam as articulações. Possuem causas e tratamentos distintos, mas por terem sintomas muito semelhantes, acabam causando confusões em seus diagnósticos. A artrite é causada por um processo inflamatório nas articulações de determinado local. Seus principais sintomas são dor, vermelhidão, inchaço e dificuldade para mover o lugar inflamado. Existem diversas doenças que podem ser diagnosticadas junto com a artrite como gota, espondilite anquilosante, artrite séptica entre outras (PINHEIRO, 2019).

Já a artrose ou osteoartrose é uma doença degenerativa que ocorre pelo desgaste do tecido conjuntivo cartilaginoso nas articulações. Pode ocorrer em qualquer articulação, mas atinge mais as das mãos, coluna, joelhos e quadril. É mais comum em pessoas idosas pelo fato de as cartilagens se desgastarem com o tempo, ocasionando o atrito direto entre ossos, o que leva a lesões nestes. Além do fator etário, genética, obesidade, diabetes e hipotireoidismo também são responsáveis pelo aparecimento da doença. ${ }^{1}$

O objetivo deste artigo consiste na investigação de ambas as doenças supracitadas: conhecer as características gerais, compreender um possível tratamento e o funcionamento de determinados medicamentos no corpo humano.

\section{METODOLOGIA}

\footnotetext{
${ }^{1}$ Disponivel em: https://www.ortopediabr.com.br/artrose-e-artrite-reumatoide/
} 
Este trabalho possui um caráter exploratório-explicativo. Exploratório devido à realização de um estudo para familiarização das doenças em questão e explicativo pelo fato de conectar fatores identificados para compreender causas e efeitos referentes às patologias. Quanto ao procedimento, a pesquisa realizar-se-á por meio da observação direta utilizando a revisão bibliográfica de sites e livros. Essas ferramentas permitem um maior acesso às informações específicas e objetivas requeridas. O material documentado será organizado em capítulos, cada um retratando um aspecto individual das doenças, separadamente.

\section{DISCUSSÃO}

A artrite é uma inflamação das articulações sinoviais, pode acometer tanto nas articulações menores, como as dos dedos e dos punhos, que são mais comuns, como também articulações maiores, como joelhos e quadril. O tipo mais comum de artrite é a chamada reumatoide, uma doença crônica com evolução progressiva que não possui uma causa conhecida, todavia é sabido que acomete mais mulheres do que homens e inicia-se entre 30 e 40 anos, sendo que sua incidência aumenta com o tempo de acordo com a Sociedade Brasileira de Reumatologia (SBR). O problema acontece porque o sistema imunológico ataca as próprias articulações do corpo, que são as regiões que ligam dois ou mais ossos revestidos por cartilagem e possibilitam que os ossos se movimentem com o mínimo de atrito possível. Com o ataque do organismo essa estrutura passa por um processo inflamatório causando vermelhidão, inchaço, dor e até perda de funções. Raramente, além das articulações, outros órgãos e tecidos podem ser prejudicados, como pele, unhas músculos, rins, coração, pulmão, sistema nervoso, olhos e sangue (SBR, 2019).

O processo em que a cartilagem começa sofrer corrosão, perdendo a capacidade de amortecer o contato entre os ossos é denominado de artrose. Essa perda da cartilagem está mais relacionada com situações de sobrecarga, como, por exemplo, em indivíduos obesos que têm mais peso sobre as articulações. A falta de atividades físicas ou também atividades em excesso, são fatores que auxiliam no desgaste das cartilagens precocemente. Existem 
localidades no corpo feminino que são comumente mais afetadas, como as mãos e os joelhos, já no corpo masculino, a região em que mais acomete a artrose é a articulação coxofemural. A artrose pode ser dividida em dois grupos: artrose primária, em que não existe uma causa para o aparecimento da doença e quando essa doença possui uma causa conhecida, é denominada de artrose secundária. Tal causa pode ser um fator hereditário, defeitos nas articulações ou até mesmo alterações no metabolismo (SBR, 2019).

\subsection{Medicamentos utilizados}

Os medicamentos indicados para artrose e artrite, são, na sua maioria, antiinflamatórios e analgésicos que diminuem a dor causada por essas anomalias. No entanto, além desses medicamentos comuns como: o paracetamol, ácido acetilsalicílico, capsaicina, fosfato sódico de prednisona, ibuprofeno e entre outras drogas, deve-se ressaltar que além delas, existem medicamentos de ação duradoura, cujos efeitos persistem mesmo após a suspensão. Assim como no caso da artrite reumatoide, recomendam-se drogas modificadoras do curso da doença que são indicados logo no começo do tratamento (LAURINDO et al., 2004).

Prednisona (substância ativa) - É indicada para o tratamento de várias doenças endócrinas, osteomusculares, reumáticas, do colágeno, dermatológicas, alérgicas, oftálmicas, respiratórias, hematológicas, neoplásicas e outras que respondam ao tratamento com corticosteroides. O tratamento corticosteroide hormonal é complementar à terapia convencional. É uma substância que proporciona potente efeito anti-inflamatório, antirreumático e antialérgico no tratamento de doenças que respondem a corticosteroides. (BRAINFARMA, 2017).

Ibuprofeno - Nome dado ao isobutilpropanoicofenólico (isobutilfenilpropanóico) é um agente anti-inflamatório não esteroidal (não derivado de hormônios) que inibe a produção de prostaglandinas (substâncias que estimulam a inflamação) o que gera atividade antiinflamatória (reduz a inflamação), analgésica (redução, até supressão, da dor) e antipirética 
(redução, até supressão, da febre). Este medicamento exerce atividades analgésicas (contra a dor) e antipiréticas (contra a febre). O início de ação ocorre cerca de 30 minutos após sua administração oral e permanece de 4 a 6 horas (PRATTI-DONADUZZI, 2003).

Reuquinol - É o sulfato de hidroxicloroquina e possui diversas ações farmacológicas, tais como interferência com a atividade enzimática, ligação ao DNA, inibição da formação das prostaglandinas, ruptura das células dos protozoários e possível interferência no aumento de produção de células de defesa. Em doenças reumáticas sua função é a inibição da interação antígeno-anticorpo, a inibição da síntese de interleucina-1 (IL-1) e da degradação da cartilagem induzida por esta citocina, além de inibir as funções lisossomais dos fagócitos e dos macrófagos. Reuquinol é indicado para o tratamento de: afecções reumáticas e dermatológicas (reumatismo e problemas de pele); artrite reumatoide (inflamação crônica das articulações); artrite reumatoide juvenil (em crianças); lúpus eritematoso sistêmico (doença multissistêmica); lúpus eritematoso discoide (lúpus eritematodo da pele); condições dermatológicas (problemas de pele) provocadas ou agravadas pela luz solar (APSEN, 2014).

Paracetamol-Sua composição é formada por (hidroximetilpropilcelulose, polietilenoglicol, crospovidona, dióxido de silídio coloidal, estearato de magnésio). Paracetamol (substância ativa) é indicado, em adultos, para a redução da febre e o alívio temporário de dores leves a moderadas, tais como dores associadas a resfriados comuns, dor de cabeça, dor no corpo, dor de dente, dor nas costas, dores musculares, dores leves associadas a artroses e dismenorreia. O paracetamol reduz a dor ao afetar os químicos nas chamadas prostaglandinas, substâncias liberadas pelo corpo em resposta a doenças ou lesões, bloqueia a produção de prostaglandinas, fazendo o corpo menos ciente da dor ou da lesão (BRAINFARMA, 2015).

Moment creme - Composto por metilparabeno, álcool etílico, cera auto emulsionante, petrolato líquido, citrato de sódio e água purificada. Este medicamento está indicado no tratamento da dor associada à neuralgia que acompanha o herpes zoster (pós-herpética), à neuropatia diabética dolorosa, à artrose, à artrite reumatoide e a outras condições que acometem os nervo, cujo princípio ativo é a capsaicina: é um analgésico tópico para alívio da dor, nas artroses e neuralgias. A capsaicina afeta a síntese, o armazenamento, o transporte e a 
liberação da Substância P, principal mensageiro químico dos impulsos da dor periférica para o sistema nervoso central (APSEN, 2015).

Artrolive - Composto por $500 \mathrm{mg}$ sulfato de glicosamina $+400 \mathrm{mg}$ sulfato de condroitina, é indicado para osteoartrite, osteoartrose ou artrose em todas as suas manifestações. Sua ação principal se faz sobre a cartilagem que reveste as articulações. O uso do medicamento por períodos superiores há três semanas demonstrou uma ação regeneradora da cartilagem, trazendo como consequência indireta a diminuição da dor e da limitação dos movimentos comuns às doenças da cartilagem. Recomenda-se evitar a ingestão de bebidas alcoólicas, durante o tratamento com Artrolive. Nos casos de história de úlcera gástrica pregressa é necessário avaliação médica e acompanhamento (ACHÉ, 2016).

\section{CONSIDERAÇÕES FINAIS}

Artrite e artrose são duas doenças diferentes, com tratamentos diferentes, porém seus sintomas são muito semelhantes podendo facilmente ser confundidos e acarretar um tratamento equivocado. Não existe uma cura para nenhum dos distúrbios abordados, porém existe o tratamento medicamentoso que pode ser feito em conjunto com outras terapias. Os medicamentos utilizados são para prevenir o avanço das doenças e também para aliviar as dores causadas por elas.

\section{REFERÊNCIAS}

ACHÉ, Laboratórios Farmacêuticos. BULA ARTROLIVE: ARTROLIVE (sulfato de glicosamina+sulfato de condroitina. $2016 . \quad$ Disponível em: <https://www.ache.com.br/arquivos/Artrolive-capsula-20-10-2016.pdf $>$ acesso em: 12 de set. 2019

APSEN, Farmacêutica S.A. REUQUINOL (sulfato de hidroxicloroquina). 2014. Disponível em: 
$<$ http://www.anvisa.gov.br/datavisa/fila_bula/frmVisualizarBula.asp?pNuTransacao $=90$ 97152015\&pIdAnexo=2895240 > acesso em: 12 de set. 2019

APSEN, Farmacêutica S.A. MOMENT CREME TÓPICO. 2015. Disponível em: $<\underline{\text { http://www.anvisa.gov.br/datavisa/fila_bula/frmVisualizarBula.asp?pNuTransacao=98 }}$ 00882015\&pIdAnexo=2938457> acesso em: 12 de set. 2019

BRAINFARMA, Indústria Química e Farmacêutica S.A. PARACETAMOL 750MG. 2015. Disponível em: <http://www.anvisa.gov.br/datavisa/fila_bula/frmVisualizarBula.asp?pNuTransacao=71 0512015\&pIdAnexo=2420805 > acesso em: 12 de set. 2019.

LAURINDO, IMM et al . Artrite reumatóide: diagnóstico e tratamento. Rev. Bras. Reumatol., São Paulo , v. 44, n. 6, p. 435-442, Dec. 2004 . Disponível em: $<\mathrm{http}: / /$ www.scielo.br/scielo.php?script=sci_arttext\&pid=S048250042004000600007\&lng=en\&nrm=iso>. Acesso em: 13 de set. 2019.

ORTOPEDIA BR. Artrose e artrite reumatoide: tudo sobre essas doenças e o sintomachave que te ajuda diferenciá-las. 2017. Disponível em: <https://www.ortopediabr.com.br/artrose-e-artrite-reumatoide/> Acesso em: 04 set. 2019.

PINHEIRO, Pedro. Diferenças entre artrite e artrose. 2010. Disponível em: 〈https://www.mdsaude.com/2010/10/artrite-artrkose.html $>$ acesso em: 19 de maio de 2019

PRATTI-DONADUZZI, Medicamentos Genéricos. IBUPROFENO. 2003. Disponível em: http://www.anvisa.gov.br/datavisa/fila_bula/frmVisualizarBula.asp?pNuTransacao=95424020 13\&pIdAnexo=1861653> acesso em: 12 de set. 2019 
PIMENTEL, Juliano. Artrose: Conheça as causas e formas de tratamentos, 2018. Disponível em: 〈https://drjulianopimentel.com.br/dores/artrose-causas-tratamentos/> Acesso em: 20 abr. 2019

PIMENTEL, Juliano. Artrite: Sintomas, causas e tratamentos. 2018. Disponível em: <https://drjulianopimentel.com.br/artigos/artrite-sintomas-causas-tratamentos/> Acesso em: 20 abr. 2019.

SOCIEDADE brasileira de reumatologia. Artrite reumatóide. 2019. Disponível em: <https://www.reumatologia.org.br/doencas-reumaticas/artrite-reumatoide/> Acesso em: 10 set. 2019.

SOCIEDADE brasileira de reumatologia. Osteoartrite (artrose). 2019 Disponível em: <https://www.reumatologia.org.br/doencas-reumaticas/artrite-reumatoide/> Acesso em: 10 set. 2019.

SANTOS, Vanessa. Articulações. 201-. Disponível em: https://www.biologianet.com/anatomia-fisiologia-animal/articulacoes.htm acesso em: 19 de maio de 2019

ZORN, T. M. T. Tecido conjuntivo.In: JUNQUEIRA L.C. (Org.).Histologia básica.10. ed. Rio de Janeiro: Guanabara Koogan S.A., 2004. p. 92-124. 